\title{
Relações Centro-Periféricas: a imperfeição de poderes entre Estados Unidos, Brasil e Venezuela
}

\author{
Center-Peripheral Relations: the imperfection of power between the United States, Brazil and Venezuela
}

DOI: https://doi.org/10.22456/2178-8839.110964

Thiago Gehre

Universidade de Brasília, Brasília, Brasil

thiago.gehre@gmail.com

(3) (ib)

Virgílio Caixeta Arraes

Universidade de Brasília, Brasília, Brasil

arraes@unb.br

\section{Resumo}

O artigo trata do relacionamento desigual recente entre Estados Unidos, Brasil e Venezuela, à luz do conceito de Centro e Periferia. Nele, Washington é o centro, ao passo que Brasília e Caracas disputam espaço na periferia do sistema, o que delineia historicamente uma relação imperfeita de poderes. Em função da diminuição da influência da Casa Branca nos últimos anos, houve a possibilidade de maior autonomia do Planalto e Miraflores em suas movimentações regionais e até globais. Todavia, isso não se sustentou por muito tempo, em decorrência de problemas políticos e econômicos internos nos dois países. Acrescente-se também que a busca por autonomia não significou o rompimento com os Estados Unidos, a despeito da retórica às vezes inflamada como no caso da Venezuela. A relação é pendular como se pôde constatar a aproximação estreita entre Donald John Trump e Michel Miguel Elias Temer e depois Jair Messias Bolsonaro. Com a substituição de Trump por Joe Biden, aguarda-se nova conformação triangular.

Palavras-chave: Centro e Periferia; Sistema Mundo; Relações Internacionais na América do Sul; Política Externa Brasileira; Venezuela;

\begin{abstract}
The article refers to the recent unequal relationship between the United States, Brazil, and Venezuela, in the light of the concept of Center and Periphery. In it, Washington is the center, while Brasília and Caracas would dispute space on the periphery of the system, which historically delineates an imperfect relationship of powers. Due to the diminished influence of the White House in recent years, there was the possibility of greater autonomy for Planalto and Miraflores in their regional and even global movements. However, this was not sustained for long, due to internal political and economic problems in both countries. It should also be added that the search for autonomy did not mean a break with the United States, despite the rhetoric sometimes ignited as in the case of Venezuela. The relationship is pendulous as we could see the close rapport between Donald John Trump and Michel Miguel Elias Temer and then Jair Messias Bolsonaro. With the replacement of Trump by Joe Biden, a new triangular conformation is awaited.
\end{abstract}

Keywords: Center and Periphery; World System; International Relations of South America; Venezuela; 


\section{Introdução}

Com a confirmação da vitória do democrata Joe Biden à Presidência dos Estados Unidos, espera-se uma necessária reviravolta na política internacional hemisférica (STUENKEL, 2020). Alguns questionamentos auxiliam a pensar sobre o tema em tela: Quais seriam os rumos adotados pelo governo de Biden com relação à América Latina, território costumeiramente pouco valorizada pela Casa Branca, a despeito da agremiação partidária à frente do poder? Como se dará mais especificamente o relacionamento entre Washington e Caracas em um contexto de desaparecimento da retórica de Donald Trump e adeptos de apoio a eventual golpe de Estado ou intervenção externa?

Em que medida a renovada Casa Branca irá modificar sua postura concernente à condução da inserção internacional do Brasil pelo Palácio do Planalto do presidente Jair Bolsonaro sob execução do ineficaz e controverso Itamaraty? Como as relações triangulares entre Washington, Brasília e Caracas continuarão sendo estruturantes para a política da região a partir de 2021? O objetivo do texto é o de refletir criticamente sob em quais condições permaneceria um “triângulo imperfeito”, ou seja, desigual, objeto, por sua vez, da estruturação do relacionamento entre os três países.

O debate sobre triunfalismo e declínio dos Estados Unidos na política global tem sido significativo nas últimas duas décadas, haja vista a manifestação de autores como Joseph Nye (2002), Immanuel Wallerstein (2004), Christopher Layne (2009) ou Niall Ferguson (2011), à mera guisa de ilustração. Justifica-se o tema em função da lenta e consistente emergência econômica da China, da consolidação política de blocos como o da União Europeia (UE), a despeito do hesitante adeus da Grã-Bretanha, e de arranjos societários como o do conhecido acrônimo BRICS (Brasil, Rússia, Índia, China e África do Sul) em que exerce Brasília papel de facto menor, principalmente em decorrência do desnorteio da política exterior da atual administração federal: neoliberalismo insipiente, apesar da ampla experiência acumulada pela chancelaria pátria desde a democratização de 1985.

Ante o exposto, Washington tem-se deparado com desgastes devido à conjugação desfavorável de fatores militares, econômicos, ambientais, humanitários e, nos últimos meses, sanitários com a inesperada pandemia oriunda do novo vírus corona entre o final de 2019 e o começo de 2020.

De fato, a ausência de uma liderança efetiva na política internacional tem gerado a intensificação da competição por terras agricultáveis (landgrabing), recursos energéticos e claro mercados consumidores, o que justifica pensar quadro mais amplo que conecte a longa duração de processos históricos com as manifestações circunstanciais sobre "hegemonia, disputas hegemônicas e interregno hegemônico” no século vinte e um. Nesse sentido, as reflexões sobre as alterações nas polaridades e na distribuição do poder no mundo implicam compreender orientações de política externa não apenas de potências como Estados Unidos, mas também a de interlocutores naturais, a depender da região. No caso da América do Sul, seriam Brasil, Argentina, Colômbia, Chile ou Venezuela.

Indo além de relações momentâneas de conflito e de cooperação ou de aproximações e de afastamentos, verifica se a conformação de um eixo de caráter eventualmente estruturante na política internacional entre a Casa Branca, o Planalto e Miraflores, que se considera para fins de visualização como um triângulo imperfeito (ARRAES; GEHRE, 2012), enquadrado conceitualmente no complexo sistema-mundo de Wallerstein.

O argumento central é o de que o ocaso relativo da primazia norte-americana produz um efeito "estilingue": em uma primeira fase, isto havia gerado maior autonomia do Brasil e Venezuela perante os Estados Unidos, ao resultar em institucionalizações e, por extensão, no fortalecimento do regionalismo; em seguida, isso recuou, em face de um realinhamento vis-à-vis das forças conservadoras, ou melhor, reacionárias nos três países, ao ter como resultante instabilidade, alimentada pela retórica de rivalidade ideológica e de rumores de possíveis intervenções na Venezuela a partir de desejos da América do Norte. Destarte, o estado de tensão perdurou ao longo de todo o mandato do presidente Donald Trump (2017-2020), reforçado em 2019 pela assunção de Jair Bolsonaro e pela continuidade com viés autoritário de Nicolás Maduro. 
O texto aborda o debate conceitual à luz da história das relações internacionais (HRI), ao tratar das dificuldades de entendimento sobre o conceito de hegemonia. Em seguida, debruça-se sobre laços contemporâneos entre Brasília, Washington e Caracas. Por último, analisam-se as consequências do relacionamento da multifacetada trinca, na qual se vislumbra a modificação das irregularidades nos contatos de poder, a partir da alteração de governo no Brasil em maio de 2016, devido ao divórcio da coligação: da parceria acomodada com o bolivarianismo para a repulsa, a datar do processo de destituição de Dilma Rousseff. O intuito é lançar luz sobre as bases recentes sob as quais se assentarão o convívio entre Estados Unidos, Venezuela e Brasil com a chegada de Joe Biden à Casa Branca.

\section{Conceitos à luz da História das Relações Internacionais}

Ao mesclar teoria e história com a finalidade de entendimento da rotina internacional, parte-se da visão crítica de que conceitos são formulados por algum motivo ou necessidade. Logo, uma abordagem qualitativa, ecumênica e orientada pela maior amplitude no estudo da origem dos acontecimentos e de seus desdobramentos é o caminho metodológico adequado Conceitos modificam-se naturalmente no correr do tempo, vez que teorias têm de incorporar de modo constante a sua base de avaliação os novos elementos do cotidiano; caso contrário, elas fenecerão, mesmo de forma gradativa, dada a irreversibilidade da obsolescência analítica ou, na melhor das hipóteses, tornar-se-ão clássicas ao ser meras fontes de consultas. (DUROSELLE, 2000; CERVO, 2008).

Visões de mundo afiguram-se cada vez mais dinâmicas, em virtude da ampliação sem precedentes da circulação de informações, haja vista o aparecimento de outros meios de divulgação, como os da internet. No passado recente - duas ou três décadas no máximo - uma das dificuldades cotidianas dos pesquisadores referia-se à restrição de acesso à massa documental, refletida ora no pouco tempo para arquivos - em função do rigor das agências de fomento quanto a prazos de encerramento de dissertações ou de teses - ora na insuficiência de recursos financeiros para a investigação de longo prazo. Outrossim, obstáculos podiam derivar de dificuldades de deslocamento - centros arquivísticos distantes em países de extensão continental como Brasil, Rússia, China ou Estados Unidos - ou de preservação para verificação posterior impossibilidade de reprodução fidedigna das coleções de documentos, via fotocópias ou fotografias.

Registros efetuados muitas vezes na pressa por conta do prazo exíguo de investigação podiam ocasionar dúvidas futuras na leitura do teor. Diante de tal quadro, o recurso à verificação encontrava-se obstado na prática, ao se considerar o impedimento de no curto prazo voltar a aceder aos locais de consulta. Outrora, a escassez documental era usual; hoje em dia, o excesso de informações compõe a rotina do pesquisador, de sorte que isto se espelha também nas tentativas de atualização conceitual, por diversas vezes de maneira insuficiente ou imprecisa (SELCHER, 2005, p.174-178).

À primeira vista, os fatos parecem ter perdido sua relevância (CHOMSKY, 2018). Destaque-se que na história, relações internacionais ou politologia a profusão de informes ambíguos ou mesmo distorcidos é significativa, em conformidade com a necessidade rotineira de preservar interesses dos Estados, de grupos políticos ou econômicos e de estadistas - da simples supressão de nomes em um texto ou de pessoas de uma fotografia à descrição incompleta de um acontecimento.

A terminologia para definir a movimentação de tal tipo de informação é bem sortida: contrainformação ou desinformação como se empregava na época da disputa bipolar e, nos últimos tempos, por influência do predomínio do idioma inglês, fake news ou pós-verdade, eufemismo grosso modo para referir-se à mentira ou polidez da diplomacia ao falseamento da realidade. Com o progresso da ciência e tecnologia, em especial nos meios de comunicação, é impossível acompanhar a circulação de dados a contento. Dessarte, a tarefa de estudar as relações internacionais de países díspares como Estados Unidos, Brasil e Venezuela demanda esforço hercúleo de selecionar, organizar e classificar documentos de vasto espectro de fontes, que retratem eventos aparentemente desvinculados.

Neste caso, o conceito central orientador deste trabalho e capaz de gerar inteligibilidade no relacionamento intricado entre Estados Unidos, Brasil e Venezuela é o de hegemonia. Autores contemporâneos analisaram sua polissemia: 
de maneira pioneira e precisa, Perry Anderson (2002, p.25-37), ao identificar as intenções dos escritos de Antonio Gramsci e ao interpretá-los a partir dos seus textos cifrados, dada a vigilância severa no cárcere da Itália fascista. Postas as condições desfavoráveis por que passava Gramsci, sua atenção se centrou na distribuição interna de poder, ao abordar o convívio entre sociedade civil - termo flexível na caracterização - e Estado e a divisão de poderes deste em três ramos.

De modo similar, Giovanni Arrighi (1996, p.27-36), ao sintetizar a formação e a consolidação do capitalismo ao longo de cerca de meio milênio (da Itália setentrional dos séculos catorze e quinze aos Estados Unidos do vinte), indica de que modo a primeira potência de determinado período ascende e decresce. Assim, ele distingue os três componentes essenciais do exercício do primeiro posto no sistema internacional: militar, econômico e cultural. Na sua visão, a prevalência incontestável - não inconteste - seria do último para o primeiro. A utilização da força seria o marco inicial da contestação da posição maior diante dos demais oponentes. Sinal de serenidade na condução singular seria a aceitação do restante da comunidade por convencimento e, por conseguinte, adesão, jamais coerção.

Pode-se afirmar que há temas ou conceitos tradicionais de definição geral sem polêmica para pesquisadores, ainda que ocorra o empreendimento constante de subdividi-los e na execução de tal tarefa divergências podem advir: guerra é um deles; diplomacia, outro. Força acima daquela ou negociação, desta. À guisa de citação, a diversificação armamentista proporcionada pela evolução científica provoca a revisão conceitual de quando em quando, ao robustecer delimitações: a datar da década de quarenta, há o surgimento de artefatos nucleares; dos anos oitenta, o surgimento dos drones ou vants (veículos aéreos não tripulados).

Por isso, eis a necessidade de modernizar conceitos: hegemonia é uma ideia em que a composição de seu delineio é controvertida, porque existem referências cotidianas a ela, como nos meios de comunicação de massa, nas quais se menciona a parte como se fosse o todo, desde que aceita a tripartição de sua constituição conforme acima citado. A palavra foi dicionarizada no vernáculo talvez pela primeira vez no Grande Dicionário Português (edição de 1873), redigido em sua maioria por frei Domingos Vieira, da ordem dos Eremitas Calçados de Santo Agostinho - falecido ele, nomes como Teófilo Braga, por duas vezes presidente da República, e Adolfo Coelho, ministro da Marinha e general de duas estrelas, complementá-lo-iam (VERDELHO, 2002, p.34-38).

Em um sistema de Estados, a oportunidade de obstar o desejo da potência ascendente de abarcar as demais seria por confrontação intensa, representada por uma coligação contra o desafiador (WIGHT, 2002, p.15; p.21-22). Quando a recém-formada Espanha, sob auspícios da dinastia dos Habsburgos, torna-se a primeira a dominar o sistema de Estados (RENOUVIN, 1967), surge como contraponto duas coligações sob liderança dos Países Baixos, ansiosos de seu desligamento da égide madrilenha e esperançosos de eles próprios assumirem o poder. Com a decadência progressiva da Espanha, em face dos custos crescentes do exercício imperial no globo, a França herdaria a preeminência na Europa, ao passo que a Holanda, a naval no Atlântico e no Índico (ARRIGHI, 1996, p.36 -47).

$\mathrm{Na}$ centúria seguinte, haveria a elevação do poderio de Londres, auxiliada ao acaso pelo relativo distanciamento do continente, ao poupá-la de participar de combates constantes como se sucedia com Madri, Paris e Amsterdam. Depois de 1815, com a derrota definitiva da França napoleônica, o poderio britânico chegaria ao ápice, ao atingir a supremacia econômica, por meio do estabelecimento da maior marinha mercante da Terra e da mais extensa rede financeira e comercial também.

Nenhuma potência do período, ainda que crescente do ponto de vista geográfico como a Rússia, por exemplo, podia equiparar-se à Grã-Bretanha. Seria o período conhecido como pax britannica, ou seja, a fase da estabilidade nas relações internacionais pela força (assegurada pela superioridade da marinha real) na prática, não a da paz. Com ela, adviriam o fim do tráfico de escravos, o combate à pirataria, a implementação do livre comércio em escala planetária, a propagação do cristianismo (anglicanismo) e a incorporação gradativa de territórios, destinados a servir de entrepostos, de bases militares ou de colonização (GOUGH, 2014). 
Em se considerando a titularidade das grandes pelejas, a sequência sintética seguiu com França no dezoito e dezenove e depois com Prússia/ Alemanha. No vinte, esta teve duas tentativas ruinosas contra a Grã-Bretanha, sendo sobrepujada na última pelos Estados Unidos e pela União Soviética, arruinada esta no tocante à infraestrutura e ampla mortandade da população. A construção de versões/narrativas históricas deve levar em consideração que a potência -mor do momento deve definir objetivos e propósitos de poder. Assim, a despeito da manutenção do status superior, ela deve buscar o concerto mundial em torno de um tema de interesse de muitos países como a estabilidade das redes comerciais ou a tranquilidade da navegação oceânica. Segundo Wight (2002, p.26), “(...) toda potência dominante aspira, ao pretender dar a unificação política à totalidade da sociedade internacional, a se tornar um império universal”.

A manutenção da soberania confunde-se em termos retóricos ou diplomáticos com a da liberdade, nem sempre estendida às populações envolvidas. Com o fito de regular a ordem pós-guerra, existe a realização de encontros ou congressos cujo resultado, caso positivo, se materializa em tratados ou acordos (KISSINGER, 2001). No século vinte, os norte-americanos, vitoriosos em grandes confrontações sem restrições três vezes, foram além: com o êxito sem precedente na Segunda Guerra Mundial, impuseram Nova York aos aliados como sede da sucedânea da Liga das Nações, fracassada no seu propósito de paz. O nome da novel instituição global seria bem sugestivo, ao repetir os termos da aliança no intenso período de confronto contra a extrema direita: Organização das Nações Unidas (ONU) (SEITENFUS, 1997; HERZ, 2004).

Simbolismos são importantes na materialização de suposta ou pretendida superioridade de países ou de governantes. Embora a palavra império não soe bem nos dias correntes, haja vista a identificação automática do termo com relações muito assimétricas entre países, o uso do conceito Centro e Periferia captura as imperfeições de poder nas relações entre EUA, Brasil e Venezuela. É possível prever que a nova política externa de Joe Biden retomará as rédeas de uma suposta hegemonia 'benigna' dos Estados Unidos, mesmo diante da ascensão econômica chinesa - que se utiliza dos tradicionais nichos e segmentos culturais ocidentais como quadrinhos e cinema - e avança com seus investimentos em regiões de típica influência ocidental, como a América Latina.

\section{Eixo desigual Washington-Brasília-Caracas}

O conceito de Sistema-Mundo de Immanuel Wallerstein abebera-se ao de Economia-Mundo de Fernand Braudel (1987, p.53-55), conforme atestado pelo próprio historiador francês; em sua essência básica, a conceituação braudeliana abrange uma determinada circunscrição no planeta, constituída como um 'todo econômico', ainda que permeável de tempos em tempos à influência de outras similares; o contato maior entre as economias-mundos poderia ocasionar, desta forma, uma modificação expressiva - ampliação de uma ou absorção de uma por outra mais pujante e viçosa. Cada uma das economias-mundos costuma-se dividir de modo tripartite: o centro assinala-se por uma cidade preponderante mais econômica que politicamente - de maneira hipotética, em se considerando o Brasil como enquadrado no centro, São Paulo ao invés de Brasília, por exemplo, seria a referência interna caso a América do Sul pudesse ser uma economia-mundo.

Com o encerramento da bipolaridade amero-soviética na virada dos anos oitenta para os noventa do século passado, a Economia-Mundo capitalista tornar-se-ia de fato a economia mundial, haja vista a ausência efetiva de contestação sistêmica - a integração econômica crescente e voluntária da China ao capitalismo, ainda que sem ser como capitulação e, ao mesmo tempo, sem aproximar-se de parâmetros internos democráticos, e a persistência de polos de resistência ou de questionamento do sistema contemporâneo (o de democracia neoliberal) de reduzido apelo à sociedade internacional como Coreia do Norte, Vietnã ou mais proximamente da América do Sul Cuba, ao ser esta uma referência nostálgica ou idealizada para agremiações partidárias (auto) consideradas à esquerda.

Nova York, São Paulo e Maracaibo (até recentemente) são em termos econômicos superiores respectivamente a Washington, Brasília e Caracas, capitais. Todavia, para o presente texto, a referência será política (diplomática). Na esteir a da perspectiva ampla de Braudel, poder-se-ia considerar Brasil e Venezuela na órbita dos Estados Unidos, avaliados estes sem dúvida como o centro, de sorte que os dois países sul-americanos comporiam uma de suas zonas, com a característica 
de dependência ou subordinação maior ou menor a depender do momento e do contexto político entre os três Estados. Seriam ambos integrantes até por razões geográficas da zona intermédia, não periférica, dos Estados Unidos. A proximidade, embora nem sempre voluntária ou aquiescida, não significa concordância constante com as emanações ou ditames do centro, de sorte que há a possibilidade de movimentação, mesmo limitada, em prol dos próprios interesses ou projetos.

A depender da intensidade da desenvoltura própria de um ou de outros dos integrantes do sistema-mundo, choques poderiam advir com o centro. Resultado disso poderia até desembocar em uma crise, conceituada por Wallerstein (2004, p.76-77) de duas formas: a frequente e causal assinalaria uma fase marcada por dificuldades internas. Contudo, a crise de fato genuína seria a sem solução à vista, ou seja, a marcada por contradições tão intensas a ponto de provocar abalos sísmicos naquele sistema; com isso, a rachadura sistêmica seria inexorável. O encaminhamento seria o concerto entre seus membros, ao menos os principais, com o propósito de rumar para uma nova conformação do sistema, após momentos de oscilações, logo de instabilidades, de duração por vezes de anos.

Com a extinção da União Soviética e com o fito de delinear a nova ordem mundial, os Estados Unidos fizeram recrudescer a globalidade da democracia neoliberal. Entretanto, a crise por que atravessa o mundo há muitos anos, com a ampliação da desigualdade e o alargamento do autoritarismo, insculpem o fracasso desse modelo. Criam-se fendas ou trincas no sistema, que se manifestam por desobediências civil, confrontações e até guerras localizadas. Na América do Sul uma série de acontecimentos chamariam a atenção do Centro para a Periferia: a eleição de projetos formalmente nacionalistas (Venezuela, Bolívia e Equador) ou trabalhistas (Brasil e Argentina); a instalação de mecanismos de participação popular anti-oligárquicas; bem com o advento de movimentos por outra globalização, movimentos indígenas e protestos contra os efeitos mais nefastos do neoliberalismo (MARTINS, 2011).

A despeito de não ter sido o único fator de impacto na eleição da Casa Branca, a crise global financeira de 2008 ajudou a acarretar a alteração de partido político no poder nos Estados Unidos - do republicano ao democrata - mas não no Brasil, cujo pleito presidencial seria realizado em outubro de 2010, e na Venezuela, ocorrido em outubro de 2012, malgrado tenha reduzido o raio de atuação no tocante a políticas sociais compensatórias, haja vista a fragilidade econômica, em especial a de Caracas, dependente ao extremo da exportação de petróleo e derivados. De acordo com Wallerstein (2004, p.87-88), a especulação é inerente à economia-mundo, em decorrência da impossibilidade de controle de organismos públicos como os bancos centrais, por exemplo, ou mesmo de instituições bancárias.

No médio prazo, nenhum dos três grupos manteria a popularidade inicial, a ponto de se sustentar com tranquilidade perante a opinião pública local: em Washington, os republicanos retornariam ao poder com o polêmico e boquirroto Donald Trump em novembro de 2016; em Brasília, apesar da vitória na disputa de outubro de 2014, a trabalhista Dilma Rousseff seria substituída, via processo de destituição, no primeiro semestre de 2016 por parceiros de coligação, representados pelo vice-presidente Michel Miguel Temer; em Caracas, embora permaneça à testa da presidência, o bolivarianismo, outrora proponente do socialismo do século vinte e um, enfrenta desgastes políticos e dificuldades econômicas inéditos em toda a sua trajetória. Causa espécie que ao invés de mitigar os efeitos da crise de 2008 a modificação - ou sua tentativa de - de dirigentes ou de agremiações partidárias nos três países acentuou a aplicação de medidas econômicas liberais (GALVÃO; LESSA; BECARD, 2019, p.83-86).

Ante o exposto, depreende-se que a nova administração de Joe Biden levará em consideração a conformação de relações desiguais de poder como fundantes à política externa hemisférica, ao reafirmar os Estados Unidos como centro, bem como ao jogar com Brasil e Venezuela como parte da periferia do sistema internacional. Na per spectiva do Sistema Mundo, a Casa Branca é polo de acumulação incessante de capital que se ancora em relações de dependência com países latino-americanos e caribenhos. A política externa de Biden deve reforçar Washington como centro produtor e exportador de know-how, tecnologia e produtos industrializados com valor agregado; enquanto Brasília e Caracas seguirão a 
coadjuvar como dependentes e periféricos na produção e exportação de insumos básicos e industrializados de menor valor agregado (CARDOSO; FALETTO, 1977; CERVO; BUENO, 2002).

Outro caminho tentativo de Brasil e Venezuela de escapar de amarras e restrições deste quadro Centro-Periferia - busca de maior autonomia - teria sido o de fortalecimento da dimensão cooperativa. Entretanto, a integração regional sul-americana acabou dobrando-se diante da multidimensionalidade do poder estadunidense, particularmente do uso inteligente da combinação entre convencimento (poder brando) e coerção (poder duro/incisivo) (NYE, 2011). Ilustra isto o fato de o recrudescimento conservador na América do Sul nos últimos anos ter aprofundado a polarização ideológica e interrompido a integração continental. A total desestruturação da União de Nações Sul-Americanas (UNASUL) gerou um vácuo institucional na gestão de crises políticas e humanitárias - como a crise migratória venezuelana - ao abrir espaço para a clara 'instrumentalização’ da Organização dos Estados Americanos (OEA) por parte de Washington. A razão de sistema da América do Sul - em bom funcionamento desde a Reunião de Brasília de 2000 (GEHRE, 2009) - sucumbiu aos ditames do Centro sobre a Periferia, com o fito de punir comportamentos considerados 'desviantes', como os do controvertido regime de Nicolás Maduro.

Mesmo que Brasil e Venezuela tenham tido episódios em suas histórias internacionais de relativa autonomia, distanciamento e certa margem de manobra política, continuariam funcionando eles como parte da periferia, pelas seguintes caracterizações: a) associações com o capital estadunidense; b) facilidades de acolher empresas de origem norteamericana; c) acesso quase total a insumos energéticos estratégicos como petróleo e gás; d) alinhamentos sem contrapartida à primeira vista para suas respectivas populações; e) atuação subimperialista em outros espaços periféricos (MARINI, 2015, p.16).

\section{Impactos da hegemonia nas relações Centro-Periferia}

O conceito de Centro e Periferia auxilia a analisar o objeto em tela a partir de pressupostos derivados do conceito de hegemonia. Primeiro, potências hegemônicas tendem ao declínio, tanto pelos altos custos do exercício cotidiano como pela extensão advinda da constante presença política, econômica, cultural e militar em diferentes regiões do mundo independentemente de ter sido solicitada ou não por outrem. A exploração da periferia planetária por um clube de países centrais torna perene a expansão do capitalismo. Isso depende de liderança que exerça controle global, ainda que em alternância de ciclos, ao visar à primazia em certos segmentos como o industrial, agrícola, comercial e de inovação tecnológica (WALLERSTEIN, 2004; ARRIGHI, 1996).

Ademais, o exercício da hegemonia em suas dimensões práticas e discursivas traz à tona as incoerências de posturas imperiais (conformação de uma estrutura no sistema mundo) e imperialistas (práticas de ampliação de poder) (BORON, 2002), em especial no sentido de evidenciar os limites militares, financeiros e humanos de sua atuação (MANN, 2013). Por último, a guerra (conflito) se torna um instrumento bem relevante para a promoção de mudanças em um contexto hegemônico, ao impulsionar ondas ascendentes de prosperidade e de crescimento ou ao resguardar o sistema de ingresso em fase descendente que ameaçaria a primazia da primeira potência (DANILOVIC, 2002).

É possível conceber a América do Sul como parte do sistema Centro-Periferia nos seguintes termos: a) preenchimento do vácuo de poder deixado pelo declínio colonial ibérico (vigente do século dezesseis ao dezenove) e uso da força (aberta e encoberta) pelos Estados Unidos como forma de tornar-se o centro de gravidade da região desde a Doutrina Monroe em dezembro de 1823; b) identidade com o processo de construção do 'império’ estadunidense ao abarcar territórios e (principalmente) mercados, porém a originar sentimento antiestadunidense perdurante até hoje em parte das sociedades do continente; c) envolvimento da região na lógica da Guerra Fria como a oposição ao comunismo como justificativa de fortalecer laços de dependência econômica e tecnológica, haja vista o lamentável exemplo do Cone Sul nas décadas de sessenta e setenta com ditaduras militares; d) menoscabo do centro com a periferia no tocante ao acesso à tecnologia de ponta, financiamento de infraestrutura, auxílio econômico e implementação de programas sociais, ao 
direcioná-las a organizações globais como Fundo Monetário Internacional (FMI) e Banco Mundial (BM); e a participação de países periféricos em aventuras subimperialistas. (MARINI, 2015; MONIZ BANDEIRA, 2005).

Com o encerramento da disputa bipolar e com a consequente dissolução da União Soviética (URSS), passou-se a visualizar a prevalência no curto prazo de um mundo unipolar, ou seja, o de um local cuja distribuição de capacidades seria uníssona. Destarte, isto poderia gerar maior estabilidade e, por conseguinte, maiores certezas sobre o comportamento futuro dos diversos atores estatais e não estatais. Entretanto, o advento do século vinte e um testemunhou duas importantes alterações geopolíticas no sistema mundo: transição da concentração de poder do Ocidente para o Oriente e difusão maior do poder de governos para atores não estatais como corporações da área de tecnologia. O impacto deste duplo processo foi justamente o da reformulação de polaridades no planeta e o do questionamento quanto à real capacidade hegemônica da Casa Branca (MOWLE; SACKO, 2007)

Todo projeto hegemônico requer convergência interna, de sorte que nos Estados Unidos republicanos e democratas têm demonstrado pouca paciência com o comportamento pendular de Caracas sob égide bolivariana: das tentativas de liderança regional diante do relativo desinteresse de Brasília à postura de oposição (mesmo retórica) a Washington. Contudo, republicanos são mais incisivos, ao passo que democratas, mais contidos ou quiçá mais envergonhados. Assim, a preocupação é similar, embora o revestimento seja distinto. Os meios de comunicação de lá colaboram com isso, ao apoiar com poucas restrições o posicionamento dos sucessivos governos norte-americanos em sua interação desigual com este vizinho ao sul.

À proporção que os demais países se afastam da vastíssima fronteira estadunidense, um e outro sobressaem aos olhos da população americana em face do regime político, da posição do dirigente-mor ou do partido no poder do momento ou da velocidade da evolução do perfil econômico através da singular cobertura da mídia e passam-se a destacar, até de maneira fugaz, aos formuladores e executores do Departamento de Estado e do Pentágono - a exagerada 'onda vermelha' ou a suposta existência de um 'eixo do mal' latino-americano são exemplos de avaliações distorcidas, frutos do desconhecimento cultural e histórico ou talvez de má fé.

O México segue como representante hispano-americano de maior importância para os Estados Unidos, entre outros motivos, por causa do comércio - acentuado pela formação do Nafta nos anos noventa - constante emigração (nem sempre legal) e narcotráfico (com ampliação da violência nas fronteiras); Cuba significa o inimigo tradicional por manter se de forma oficialmente comunista há seis décadas ininterruptas, a despeito das reformas efetuadas nos últimos anos; Hugo Chávez, Evo Morales ou Rafael Correa se encaixaram pela retórica nacionalista, socialista ou até antiamericana idealizada sob o renovado manto do bolivarianismo bem como o Partido Justicialista na Argentina, em resultado do espectro de Juan Domingo Perón e da família Kirchner (HOBSBAWM, 2020). A Colômbia - em um complicado e demorado processo de paz - por conta dos embates com guerrilhas originalmente de esquerda ou, segundo o governo, associadas com o narcotráfico, possui situação bem específica no contexto continental, ao ser o mais militarizado dentro do quadro formalmente democrático desdobrado na bipolaridade.

Outra característica do agir hegemônico é o pensar que descaracteriza configurações diversificadas como a latinoamericana. O resultado é que a região costuma ser menosprezada por mandatários estadunidenses, malgrado a agremiação no poder. Assim, acaba-se por impor às elites locais um padrão de pensamento alinhado e um modus operandi dócil, de modo que gestores ibero-americanos sigam de boa vontade os ideários sugeridos por Washington de tempos em tempos - anticomunismo na Guerra Fria ou neoliberalismo nas últimas três décadas. Questionamentos das recomendações são comuns, porém não a ponto de interromper a execução de parcerias duradouras.

Além disso, a liderança dos Estados Unidos se exerce por 'manuais' como o do Consenso de Washington da década de noventa: em suma, conjunto de prescrições por meio do qual se mesclavam medidas de austeridade fiscal e privatizações maciças. Sem avaliação estratégica para a economia nacional e, portanto, sem extensão de benefícios gerais à sofrida população, estas ideias foram bem disseminadas nos organismos regionais e palácios - designação inaceitável para uma 
área republicana desde o século dezenove - presidenciais. A reação anti-hegemônica, ainda que não tão desafiadora, veio com a onda palidamente vermelha ou nacionalista na América do Sul na viragem do milênio. Na América do Sul, o mais popular tenha sido talvez Luís Inácio Lula da Silva que aludia como "a administração petista (com muito mais sucesso, aliás, do que as suas aparentadas na Venezuela, no Equador e na Argentina)” teria implantado políticas distributivas com resultados excepcionais tendo, portanto, "seu dia de partido socialdemocrata bem-sucedido no continente americano" (ALENCAR, 2017, p.80).

Entrementes, o mais polêmico foi sem sombra de dúvida Hugo Chávez, militar de formação, por ter ressuscitado o supracitado bolivarianismo e tê-lo revigorado por um período; de modo posterior, ele disseminou-o, a despeito da sustentação material da doutrina amparar-se em fator externo, ou seja, na variável cotação do petróleo. Assim, a população da região assistiu ora entusiasmada, ora atônita à ascensão disso na transição do milênio sob a liderança carismática do venezuelano. Perante a decepção real com o ideário neoliberal em termos sociais em curto prazo, a outra opção, mesmo sob tinturas populistas, terminaria por chamar a atenção do povo.

A reação brasileira pôde ser qualificada como tíbia porque o relacionamento entre Brasília e Washington era regular, ao concentrar a Casa Branca a atenção no comércio, esperançosa de exportar produtos industrializados e serviços e importar matérias primas e produtos agrícolas, e o Planalto, na política, ao aspirar de maneira quimérica ao assento perpétuo do Conselho de Segurança da Organização das Nações Unidas (CS/ONU) - o incontido desejo remonta à constituição do organismo quando Washington mostrou-se favorável, mas sem conseguir o apoio de Moscou e Londres (WEISS; ROY, 2017).

Outro ponto importante entre os dois gigantes é a presença maciça dos emigrados - estima-se quantia próxima do milhão e meio de brasileiros em solo estadunidense. Deslocam-se há décadas os nacionais em busca de condições de vida mais apropriadas, ou seja, menos desiguais em termos sociais, com melhor oportunidade de emprego e mais seguras quanto ao convívio. Saliente-se que estatísticas de brasileiros no exterior - estima-se acima de três milhões - são imprecisas por conta da movimentação oscilante de pessoas em função de aspectos como vencimento do prazo dos vistos ou ritmos distintos de crescimento das economias (CORDEIRO, 2018).

A transição da administração republicana de George W. Bush (2001-2008) para a do democrata Barack Obama (2009-2016) não envolveu alterações significativas na política exterior para a região, a despeito da suposta diferença nas idealizações políticas e das expectativas até inesperadas, haja vista as manifestações populares durante aquela campanha presidencial. Isso talvez ocorra porque à medida que o tempo passa as diferenças entre republicanos e democratas tem -se tornado bastante tênues, isto é, mais epidérmicas. Os meios de comunicação chegaram a registrar isso quase de forma folclórica mediante declarações de presidentes norte-americanos sobre suas contrapartes brasileiras como a de abril de 2009 no encontro do G-20 de 2009. Obama teria dito: "Este é o cara, bem aqui, eu o admiro. Ele é o político mais popular do globo"1 (STEWART, 2009, tradução livre). Como lembra John French (apud VERA, 2009; CHACRA, 2010), sobre a relação entre Lula da Silva e George Bush: “Eles tinham bastante afinidade, mais até do que Lula e Obama têm”.

Estados Unidos, Brasil e Venezuela passaram há alguns anos por processos de mudança de governantes, embora sob formas bastante diferentes. Com o falecimento de Hugo Chávez, ascendeu Nicolás Maduro em 2013; com a destituição da petista Dilma Rousseff, subiu o peemedebista Michel Miguel Temer em 2016. Com a saída do democrata Barack Obama, venceu o republicano Donald Trump nos Estados Unidos em 2016.

Em 2015, quando os principais partidos políticos estadunidenses analisavam os possíveis candidatos à sucessão de Barack Obama o nome de Donald Trump aparecia cá e acolá, porém de maneira fanfarrona, dada sua costumeira blasonaria. A princípio, ele compor o vasto quadro de aspirantes presidenciais parecia ser oportuna medida de autopromoção, algo a que o público estava acostumado. No entanto, sua candidatura começou a superar a dos demais competidores. Antipatia ou repugnância por um lado, porém simpatia com segmentos mais reacionários ou descontentes

\footnotetext{
1 "Here's my man, right here, I love this guy. He's the most popular politician on Earth"
} 
com o status quo da democracia local ou com sua própria situação socioeconômica - como os do 'Rust Belt', onde trabalhadores acompanhavam com desânimo desindustrialização e empobrecimento regional.

Descortês ao extremo, o capitalista chegou a questionar o valor cívico do senador John McCain quando tenente aviador da Marinha na Guerra do Vietnã, por ter sido capturado pelo inimigo, ao ter a aeronave abatida em outubro de 1967. Críticas generalizadas e acerbas a imigrantes mexicanos ou islâmicos também figuraram como demonstrações inequivocamente racistas, ao considerá-los como potencialmente desrespeitosos à lei estadunidense, de sorte que se romperia a tradição de acolhimento, independentemente da origem social, religiosa, cultural ou geográfica (BBC, 2016).

Diante disso, seus índices eleitorais, apesar das expectativas, não se reduziriam por causa das falas controvertidas e xenófobas. Por outro, a esperança dos adversários residia na expectativa de que seu limite natural de crescimento não alcançaria índice elevado. Seus potenciais eleitores incluíam-se entre os segmentos menos escolarizados e de classe média baixa ou pobres. Conquanto tenha sido derrotado entre a população pela margem de dois pontos percentuais, algo em torno de dois milhões de votos a menos, Trump superou sua antagonista, Hillary Clinton, com relativa facilid ade no colégio dos delegados, ao atingir mais de três centenas de votos do total de quinhentos e quarenta.

A desmobilização do projeto regionalista coadunou com as linhas de ação da política externa brasileira (PEB) implementadas por José Serra Chirico, senador de São Paulo, na reduzida gestão à frente da chancelaria (maio de 2016 a fevereiro de 2017), e reforçadas por seu sucessor, Aloysio Nunes Ferreira Filho. O objetivo era o de realinhar Brasília aos desígnios de Washington, em detrimento da parceria tática consolidada nos últimos anos com a bolivariana Caracas (SERRA, 2016).

Nada obstante, as três sucessões acabaram por impactar nos contatos entre Estados Unidos-Brasil-Venezuela, dando-lhe novo contorno devido aos 'ângulos' ainda mais conservadores. Com isso, voltou a caracterização das relações imperfeitas de poder à luz do conceito de Centro e Periferia. De forma bem desigual, leve-se em conta o porte econômico de cada um dos três países, porque eles se deparam com um emaranhado complexo de relacionamento estabelecido a partir da reconfiguração das polaridades globais - com naturais impactos regionais - da inexorável elevação chinesa além da Ásia e do retorno de forças mais conservadoras/reacionárias no intricado xadrez político planetário, vez que as composições consideradas progressistas falharam na materialização do seu ideário verbalizado.

\section{Considerações finais}

Este artigo buscou lançar luz sobre os desafios enfrentados por Brasil (potência regional, apesar dos percalços políticos em andamento) e Venezuela (potência sub-regional, em decorrência da decadência econômica de anos contínuos) diante do reposicionamento dos Estados Unidos com a polêmica presidência de Donald Trump ao ter que enfrentar a nova 'normalidade' da política global: a ascensão chinesa e a feroz competição desencadeada nas regiões periféricas como América Latina e África.

Para os Estados Unidos retomarem as rédeas hegemônicas da ordem planetária, é necessário realinhar seus aliados, em especial os mais próximos geograficamente como Brasil e Venezuela, apesar dos antagonismos momentâneos. Com o primeiro, não houve problema, dado que partiu de Brasília em 2016 o desejo de aproximar-se sem ressalvas de Washington. Mesmo com críticas acerbas recentes da Casa Branca ao país, por causa do descontrole do espraiamento do vírus corona, o Planalto manteve a inadequada postura de admiração irrefreada.

Com Caracas, a situação é bastante diferente porquanto, apesar do fracasso administrativo do governo bolivariano e da inclinação sem pejo ao autoritarismo, a oposição não consegue qualificar-se para apresentar à sofrida população um projeto atraente do ponto de vista de diversidade partidária e de valorização de políticas sociais, ao limitar se a clamar de forma pública a substituição de dirigentes tão somente. Nem sequer com o inegável esgarçamento da oligarquia atual, os desafiantes logram superá-la pelo voto. 
Nos últimos tempos, o desgaste das gestões de Trump e de Bolsonaro tem preservado a de Maduro no plano regional. Conforme exposto ao longo do texto, as dificuldades conceituais se encontram no plano das práticas hegemônicas, por causa da complexidade da realidade recortada. Destarte, empregar um conceito 'cristalizado' ou melhor fossilizado é menoscabar a dinâmica dos acontecimentos em todas as suas vertentes. Pela amplitude do campo das relações internacionais, a atualização, a partir da interpretação, se faz constante, até em virtude da revolução global da informação e mais recentemente dos prospectos de avanço nas fontes energéticas, biotecnologia e inteligência artificial

Sem hesitação, pode-se afirmar que o relacionamento de Brasil, Estados Unidos e Venezuela têm sido fruto de ambivalência entre modificações sistêmicas, ao contemplar a erosão do poder estadunidense ao tempo do crescimento chinês bem como os particularismos e voluntarismos de grupo e de indivíduos na construção de uma trajetória oscilante entre momentos mais tranquilos ou conflituosos como agora por conta da pandemia do vírus corona e dos seus efeitos negativos sobre todo o comércio planetário.

Pode-se especular que o posicionamento de Caracas, voltado para a integração regional com a subida do bolivarianismo há quase um quarto de século, tenha obrigado Brasília, sob auspícios oficialmente trabalhistas entre 2003 e 2016, a se movimentar além do Cone Sul (o Mercosul). Com o declínio gradativo da política externa de extração bolivariana, amparada de modo indevido por muito tempo no preço do petróleo, o Planalto terminou por acomodar -se, ao não vislumbrar rival algum à altura.

Diante da disputa ou da diferença não declarada de ambos, a postura da Casa Branca foi a de valorizar o Brasil, por já se fiar no comportamento mais comedido do governo de Lula da Silva e depois do de Dilma Rousseff. Assim, transformá-lo-ia no mediador sul-americano, até por não propor o país, sob manto trabalhista, alterações de monta na sociedade internacional, a não ser na retórica em fóruns globais como a reforma do Conselho de Segurança da Organização das Nações Unidas.

A transição política entre governos de bases partidárias diferentes - ao menos em termos oficiais ou tradicionais, vez que siglas das agremiações hoje pouco significam quando se cotejam seus nomes com a essência ou com a prática como se pôde verificar entre o republicano George Bush e o democrata Barack Obama, entre administrações de firmamento ideológico semelhante, como se pôde observar com Lula da Silva e Dilma Rousseff, ambos trabalhistas, ou com Hugo Chávez e Nicolás Maduro, ambos bolivarianos, não leva necessariamente a alterações profundas em matéria de política externa.

Em síntese, em decorrência da consolidação de determinadas posturas, convertidas em política de Estado ou em designíos estratégicos, avalia-se que a nova presidência do democrata Joe Biden deverá trabalhar em torno de garantir segurança energética e de assegurar estabilidade continental, o que passaria por garantir os negócios do petróleo e os interesses econômicos de Caracas, malgrado as divergências das últimas décadas.

Da mesma maneira, Miraflores não deverá renunciar aos recursos norte-americanos, ainda que siga uma toada retórica de oposição aos Estados Unidos, mantendo-se afastada das concertações diplomáticas com um Brasil neoliberal e conservador. Por fim, a despeito de perder seu principal ícone político e, portanto, referencial hemisférico, por causa da derrota eleitoral do presidente Donald Trump em novembro de 2020, o Planalto deverá sentir-se obrigado a ter de renegociar seu status regional na América Latina, porque haveria o risco de ser menosprezado em um novo desenho geopolítico na região, no qual outros países, ainda que de menor porte, se tornem mais relevantes estrategicamente ao centro de poder hemisférico - Washington - nos próximos quatro anos.

\section{Referências}

ANDERSON, Perry. Afinidades seletivas. São Paulo: Boitempo, 2002.

ALENCAR, José Almino de. Gordos, magros e guenzos. Recife: Companhia Editora de Pernambuco, 2017. 
ARRAES, Virgílio; GEHRE, Thiago. O Brasil entre Washington e Caracas: história e política externa (1902-2012). In: AVILA, Carlos Federico Dominguez. (Org.). Política, cultura e sociedade na América Latina: estudos interdisciplinares e comparativos. Curitiba: CRV, 2012, v. 1, p. 220-248.

ARRIGHI, Giovanni. O longo século XX. Rio de Janeiro: Contratempo, 1996.

BANDEIRA, Luiz Alberto Moniz. Formação do Império americano. Rio de Janeiro, Civilização Brasileira, 2005.

BARBARA, Vanessa. Brazil, the Outlaw's Paradise. New York Times. New York, 6 jun. 2015. Disponível em: https://www.nytimes.com/2015/02/06/opinion/vanessa-barbara-brazil-the-outlaws-paradise.html. Acesso em 10 jul. 2020

BBC. 'Drug dealers, criminals, rapists': What Trump thinks of Mexicans. BBC. London. 31 aug. 2016. Disponível em: https://www.bbc.com/news/av/world-us-canada-37230916. Acesso em 10 ago. 2020

BORON, Atílio. Império. Imperialismo. Buenos Aires: Clacso, 2002.

BRAUDEL, Fernand. A dinâmica do capitalismo. Rio de Janeiro: Rocco, 1987.

CARDOSO, Fernando Henrique; FALETTO, Enzo. Dependência e desenvolvimento na América Latina. 4 ed. Rio de Janeiro: Zahar, 1977.

CERVO, Amado. Inserção internacional. São Paulo: Saraiva, 2008

CERVO, Amado; BUENO, Clodoaldo. História da política exterior do Brasil. 2 ed. Brasília: Universidade de Brasília, 2002.

CHACRA, Guga. De Washington a Brasília - Lula era amigo de Bush; FHC, de Clinton. E Dilma e Obama? Estado de São Paulo. São Paulo, $1^{\mathrm{o}}$ nov. 2010. Disponível em: https://internacional.estadao.com.br/blogs/gustavo-chacra/de-washington-a-brasilia-lula-era-amigode-bush-fhc-de-clinton-e-dilma-e-obama/. Acesso em 8 jul. 2020.

CHOMSKY, Noam. Noam Chomsky: “As pessoas já não acreditam nos fatos”. El Pais. Madri, 12 mar. 2018. Disponível em: https://brasil.elpais.com/brasil/2018/03/06/cultura/1520352987_936609.html. Acesso em 9 jul. 2020.

CORDEIRO, Tiago. O que acontece quando um brasileiro decide ir morar nos EUA. Gazeta do Povo. Curitiba, 15 abr. 2018 . Disponível em: $\quad$ https://www.gazetadopovo.com.br/ideias/o-que-acontece-quando-um-brasileiro-decide-ir-morar-nos-euabo0rdh9fuawlhsj35lojkuaq0 . Acesso em 8 jul. 2020.

DANILOVIC, Vesna. When the stakes are high: deterrence and conflict among major Powers. University of Michigan 2002.

DUROSELLE, Jean Baptiste. Todo império perecerá. Brasília: Universidade de Brasília, 2000.

FERGUSON, Niall. Civilização: Ocidente x Oriente. São Paulo: Planeta, 2011.

GALVÃO, Thiago Gehre. América do Sul: uma ideia brasileira em marcha. Curitiba, Juruá, 2009.

GALVÃO, Thiago Gehre; LESSA, Antônio Carlos Moraes; BECARD, Danielly Silva Ramos. Rise and fall of triumphalism in Brazilian foreign policy: the international strategy of the Workers Partys 's governments (2003-2016). In: Status and the rise of Brazil. ESTEVES, Paulo; JUMBERT, Maria Gabrielsen; CARVALHO, Benjamin. (Eds). London: Palgrave Macmillan, 2019, p.71-88.

GOUGH, Barry. Pax Britannica. Ruling the Waves and Keeping the Peace before Armageddon. London: Palgrave MacMillan, 2014.

HERZ, Mônica. Organizações internacionais: história e práticas. Rio de Janeiro: Elsevier, 2004.

HOBSBAWM, Eric. Projeto norte-americano está falindo. Folha de São Paulo. São Paulo, 22 set. 2020. Disponível em: https://www1.folha.uol.com.br/folha-100-anos/2020/09/projeto-norte-americano-esta-falindo-disse-hobsbawm-a-folha-em2007.shtml. Acesso em 23 set. 2020

KISSINGER, Henry. Diplomacia. Rio de Janeiro: Francisco Alves, 2001.

LAYNE, Christopher. The Waning of US Hegemony - myth or reality. International Security, v.34, n.1, 2009.

MANN, Michael. The sources of social power. V.4. Globalizations, 1945-2011. Cambridge University, 2013.

MARINI, Ruy Mauro. América Latina, dependencia y globalización. Buenos Aires: Siglo XXI; CLACSO, 2015.

MARTINS, Carlos Eduardo. Globalização, dependência e neoliberalismo na América Latina. São Paulo: Boitempo, 2011

MOWLE, Thomas; SACKO David. The Unipolar World an Unbalanced Future. London: Palgrave Macmillan, 2007.

NYE, Joseph. O paradoxo do poder americano. São Paulo: Universidade Estadual Júlio de Mesquita, 2002.

NYE, Joseph. The future of power. New York: Public Affairs, 2011.

RENOUVIN, Pierre. Introdução à história das relações internacionais. São Paulo: Difusão Europeia do Livro, 1967. 
SEITENFUS, Ricardo. Manual das organizações internacionais. Porto Alegre: Livraria do Advogado, 1997.

SELCHER, Wayne A. Use of Internet Sources in International Studies Teaching and Research. International Studies Perspectives. Oxford, v.6, n.2, p. 174-189, 2005.

SERRA, José. Discurso do ministro José Serra por ocasião da cerimônia de transmissão do cargo de ministro de estado das Relações Exteriores. Ministério das Relações Exteriores. Brasília, 18 maio 2016. Disponível em: http://www.itamaraty.gov.br/discursosartigos-e-entrevistas-categoria/ministro-das-relacoes-exteriores-discursos/14038-discurso-do-ministro-jose-serra-por-ocasiao-dacerimonia-de-transmissao-do-cargo-de-ministro-de-estado-das-relacoes-exteriores-brasilia-18-de-maio-de-2016. Acesso em 22 set. 2020 .

STEWART, Brian. The most popular politician on Earth. CBC. Toronto, 7 may 2009. Disponível em: https://www.cbc.ca/news/world/the-most-popular-politician-on-earth-1.810078. Acesso em 14 jul. 2020.

STUENKEL, Oliver. Trump Drove Latin America Into China's Arms Biden Has a Chance to Wrest It Back. Foreign Affairs. New York, 13 nov. 2020. Disponível em: https://www.foreignaffairs.com/articles/south-america/2020-11-13/trump-drove-latin-america-chinasarms. Acesso em 10 dez. 2020.

VERA, Andres. Breve história da amizade entre presidentes. Época. Rio de Janeiro, 27 nov. 2009. Disponível em: http://revistaepoca.globo.com/Revista/Epoca/0,EMI107284-15227,00BREVE+HISTORIA+DA+AMIZADE+ENTRE+PRESIDENTES.html. Acesso em 14 jul. 2020.

VERDELHO, Telmo. Dicionários portugueses, breve história. In: NUNES, Jose; PETTER, Margarida (Eds). História do saber lexical e constituição de um léxico brasileiro. São Paulo: Universidade de São Paulo; Pontes, 2002, p.15-64.

WALLERSTEIN, Immanuel. World-Systems Analysis: an introduction. Durham and London: Duke University, 2004

WEISS, Thomas; ROY, Pallavi. The UN and the Global South, 1945 and 2015. New York: Routledge, 2017

WIGHT, Martin. A política do poder. Brasília: Fundação Alexandre de Gusmão, 2002.

\begin{tabular}{ll}
\hline Funções de colaboração exercidas & \\
\hline Thiago Gehre: & Escrita (revisão e edição); \\
Virgilio Caixeta Arraes: & Escrita (revisão e edição); \\
\hline
\end{tabular}

